\title{
Effect of Synthesis Methods on Properties of Copper Oxide Doped Titanium Dioxide Photocatalyst in Dye Photodegradation of Rhodamine B
}

\author{
Cheng Yee Leong ${ }^{1}$, Hao Lin Teh', Man Ching Chen'ㄹ, Siew Ling Lee1,2* \\ ${ }^{1}$ Department of Chemistry, Faculty of Science, Universiti Teknologi Malaysia, 81310 Johor Bahru, Malaysia \\ ${ }^{2}$ Centre for Sustainable Nanomaterials, Ibnu Sina Institute for Scientific and Industrial Research, Universiti Teknologi Malaysia, 81300 Johor Bahru, Malaysia \\ *Corresponding author: Isling@utm.my
}

\begin{abstract}
Copper oxide modified titanium dioxide photocatalysts have been widely reported for their excellent performance in the wastewater treatment. However, there is lack of information on the effect of different synthesis methods towards the properties and catalytic activity of the photocatalyst. In this research, a series of copper oxide doped titanium dioxide $\left(\mathrm{Cu}-\mathrm{TiO}_{2}\right)$ photocatalysts were synthesized via three different methods of sonochemical, impregnation and physical mixing. $\mathrm{Cu}-\mathrm{TiO}_{2}$ of varied molar ratios of $\mathrm{Cu}$ dopant to $\mathrm{TiO}_{2}$ TR595 (1:99, 2:98, 3:97 and 4:96) were prepared. Comparison of physical-chemical properties and photocatalytic activity among the synthesized samples and unmodified $\mathrm{TiO}_{2} \mathrm{TR}_{595}$ were made. X-ray diffraction analysis depicted the formation of $\mathrm{TiO}_{2}$ rutile phase in all samples. Besides, diffuse reflectance UV-visible analysis proved that the synthesized samples were active under visible light region. According to the Tauc plot and photoluminescence spectra, the band gap energies and recombination rate of electron-hole pairs of $\mathrm{Cu}-\mathrm{TiO}_{2}$ samples decreased upon loading of $\mathrm{Cu}$. Moreover, EDX analysis confirmed the existence of Ti and $\mathrm{Cu}$ in all the samples. The photocatalytic efficiencies of the synthesized samples were discovered through photodegradation of Rhodamine $\mathrm{B}$ organic dye under 6 hours of visible light irradiation. Amongst, $\mathrm{Cu}-\mathrm{TiO}_{2}$ photocatalysts synthesized via sonochemical method with molar ratio of 2:98 produced the highest photocatalytic activity of $65 \%$ which attributed to the lowest recombination rate of photogenerated charge carriers and availability of large number of reactive oxidative species.
\end{abstract}

Keywords

Copper Oxide Doped Titanium Dioxide, Photocatalyst, Sonochemical, Impregnation, Physical Mixing, Rhodamine B

Received: 16 September 2021, Accepted: 3 December 2021

https://doi.org/10.26554/sti.2022.7.1.91-97

\section{INTRODUCTION}

Titanium dioxide $\left(\mathrm{TiO}_{2}\right)$ and its composites have excellent chemical stability and corrosion-resistance ability with favour able mechanical performance. There are three phases in $\mathrm{TiO}_{2}$ which are anatase, rutile, and brookite. The activation of $\mathrm{TiO}_{2}$ happens under ultraviolet light due to its wide bandgap of 3.2 $\mathrm{eV}$ for photoactivity. In other words, $\mathrm{TiO}_{2}$ has limited photocatalytic activity under visible light. Apart from that, the high electron-hole pairs recombination rate of $\mathrm{TiO}_{2}$ has reduced its quantum efficiency (Leong et al., 2021). As a result, modification of $\mathrm{TiO}_{2}$ has been conducted using different metals or metal oxides to broaden its absorption spectra to visible light region (Koh et al., 2017; Koh et al., 2020; Ooi et al., 2020; Ooi et al., 2016). Properties of $\mathrm{TiO}_{2}$ could be improved by doping of $\mathrm{Cu}$ compounds due to their high conductivity and low toxicity (Isa et al., 2020; Sabran et al., 2019). More importantly, $\mathrm{Cu}$ significantly extends the light response of $\mathrm{TiO}_{2}$ into the visible region in solar energy area and the existence of $\mathrm{Cu}$ metal on $\mathrm{TiO}_{2}$ could obviously influence the particle size as well as oxygen number or intermediate species on $\mathrm{TiO}_{2}$ surface (Zuas and Budiman, 2013). The suitable amount of the addition of $\mathrm{Cu}$ dopant was able to cause electron trapping and suppress the electron-hole recombination, thus improving the photocatalytic degradation rates greatly compared with bare $\mathrm{TiO}_{2}$ (Neena et al., 2018). Besides, $\mathrm{Cu}$-doping into/onto $\mathrm{TiO}_{2}$ decreased the band gap significantly to increase the photoactivity rate in visible light region. As a result, the absorption capacity for aromatic organic pollutants enhanced drastically after the doping of $\mathrm{Cu}$ to $\mathrm{TiO}_{2}$.

Various methods have been applied for the synthesis of $\mathrm{Cu}-\mathrm{TiO}_{2}$ photocatalysts. Sonochemical method could be conducted via an ultrasonic bath or by using a probe type ultrasonic homogenizer to obtain the desired effects from ultrasonication including homogenization, extraction, deagglomeration, dispersing, emulsification and disintegration (Sahrin et al., 2020). On the other hand, impregnation method involved procedure 
whereby active precursor that contained within a certain volume of solution was contacted with the solid support, which then the mixture was dried to remove the imbibed solvent (Deraz, 2018). The impregnation method was considered a fast and inexpensive approach. More importantly, it allowed determination of configuration, crystallography and morphology of $\mathrm{TiO}_{2}$ final products to be controllable in advance (Deraz, 2018). Physical mixing method is also known as mechanical mixing method. It is an alternate, simple and cost-effective synthesis method that enables formation of composites in better hybrid structures that would having chemical and mechanical advantageous properties for industrial production (Megha et al., 2018). The utilization of this method in $\mathrm{Cu}-\mathrm{TiO}_{2}$ photocatalyst synthesis for dye photodegradation aspect is yet to be known.

In this work, different synthesis methods of sonochemical, impregnation and physical mixing methods were applied to synthesize $\mathrm{Cu}-\mathrm{TiO}_{2}$ photocatalysts. The physicochemical properties and photocatalytic performance of the resulting photocatalysts were examined. The direct comparison would be important to understand the effect of the synthesis methods on the properties and photocatalytic performance of these titania-based catalysts.

\section{EXPERIMENTAL SECTION}

\subsection{Photocatalysts Preparation}

A series of $\mathrm{CuO}$ doped $\mathrm{TiO}_{2}$ photocatalysts were prepared via sonochemical method. For this purpose, appropriate amount of pure rutile $\mathrm{TiO}_{2}$ TR595 powder $(\geq 99.0 \%)$ was used as starting precursor. The $\mathrm{TiO}_{2}$ precursor was added into a beaker together with the presence of $2.5 \mathrm{~mL}$ propylene glycol (Merck, $\geq 99.0 \%$ ) and $26.5 \mathrm{~mL}$ water. After that, the mixture was stirred for 5 minutes. Sodium hydroxide (Merck, $\geq 99.0 \%$ ) was then added dropwise to the mixture until about $\mathrm{pH}$ 8-9 of solution was obtained. Again, the reaction mixture was stirred for another 5 minutes. Next, appropriate amount of copper(II) nitrate trihydrate (Merck, $\geq 99.0 \%$ ) was added to the mixture and stirred for 15 minutes. The molar ratio of $\mathrm{TiO}_{2}$ to $\mathrm{Cu}$ dopant was set at 98:2. After that, the ultrasonication process was carried out for a duration of 15 minutes at $91 \mathrm{~W}$. Eventually, the precipitate was dried in an oven to obtain the $\mathrm{CuO}$ doped $\mathrm{TiO}_{2}$ powder.

Meanwhile, a solution of copper precursors was prepared for capillary impregnation method. This was done by dissolving copper(II) nitrate trihydrate in $50 \mathrm{~mL}$ of distilled water. After that, the solution was stirred for 30 minutes at room temperature. Subsequently, appropriate amount of pure rutile $\mathrm{TiO}_{2}$ TR595 powder was added to the solution. It was noted that the molar ratio of $\mathrm{TiO}_{2}$ to $\mathrm{Cu}$ dopant was fixed at 98:2. The reaction mixture was then stirred for another 2 hours. At last, the sample obtained was dried in an oven.

The physical mixing method was conducted with the direct application of copper(II) nitrate trihydrate and pure rutile $\mathrm{TiO}_{2}$ TR595 without any further treatment. The samples were mechanically mixed in a beaker for 2 hours. The molar ratio of $\mathrm{TiO}_{2}$ to copper(II) nitrate trihydrate was set as 98:2. After finishing the mechanical mixing process using magnetic stirrer, the reaction mixture was dried in an oven. Samples of different $\mathrm{TiO}_{2}$ to $\mathrm{Cu}$ molar ratios of 99:1, 97:3 and 96:4 were also prepared via the three methods mentioned above. All the samples prepared were denoted at $\mathrm{x} \mathrm{Cu}: \mathrm{TiO}_{2}, \mathrm{x}=$ molar ratio of $\mathrm{Cu}$ to $\mathrm{TiO}_{2}$.

\subsection{Characterizations}

The crystalline phases and crystal structures of the samples were examined with the technique X-ray Diffractometry (XRD). Bruker Advance D8 was applied with $\mathrm{Cu} \mathrm{K} \alpha$ irradiation $(\lambda=$ $0.15406 \mathrm{~nm}, 40 \mathrm{KV}, 40 \mathrm{~mA}$ ) and the samples were scanned in the range $2 \theta=2-80^{\circ}$ with step size $0.05^{\circ} / \mathrm{s}$ to obtain the XRD patterns. UV-Vis spectrometer (Perkin- Elmer Lambda 35) equipped with integration sphere $\left(\mathrm{BaSO}_{4}\right.$ coated $\left.76 \mathrm{~mm}\right)$ was applied to study the optical properties of the samples. Appropriate amount of sample was placed on the sample holder and scanned at wavelength ranged from 200 to $800 \mathrm{~nm}$ to collect the spectrum. Tauc plot was used to determine the band gap energy of the samples. It was plotted as $(\alpha \mathrm{h} v) 2$ against $\mathrm{h} v$, where $\alpha$ was the diffuse reflectance spectra absorbance, $\mathrm{h}$ was the Planck constant and $v$ was the frequency of light. Photoluminescence spectroscopy (JASCO, FG-8500) with an excitation of $310 \mathrm{~nm}$ was used to study the rate of electron-hole recombination of the samples. The morphology of the selected samples was confirmed with Field Emission Scanning Electron Microscopy (FESEM). Field emission scanning electron microscope (Hitachi SU8020) coupled with EDX analyser was utilized to scan the samples in order to produce high quality images and to confirm the elements present in the selected samples.

\subsection{Photocatalytic Testing}

Photocatalytic testing was conducted by using $50 \mathrm{~mL} 15 \mathrm{ppm}$ Rhodamine $\mathrm{B}$ and $0.05 \mathrm{~g}$ samples and irradiated under $15 \mathrm{~W}$ LED light source for 6 hours. Prior to reaction, adsorption was carried out to ensure the decreased concentration of Rhodamine $\mathrm{B}$ was attributed solely to photodegradation. The photocatalytic performance of each synthesized $\mathrm{Cu}-\mathrm{TiO}_{2}$ sample was calculated according to the formula below:

$$
\text { Photodegradation efficiency }(\%)=\frac{C_{0}-C_{t}}{C_{0}} \times 100 \%
$$

where, $\mathrm{C}_{0}=$ Concentration of Rhodamine $\mathrm{B}$ before reaction $(\mathrm{ppm}), \mathrm{C}_{t}=$ Concentration of Rhodamine $\mathrm{B}$ after reaction (ppm)

\section{RESULTS AND DISCUSSION}

\subsection{Structural Properties}

Figure 1 displays the XRD diffraction patterns of $\mathrm{Cu}-\mathrm{TiO}_{2}$ samples with varied molar ratios which were synthesized via 


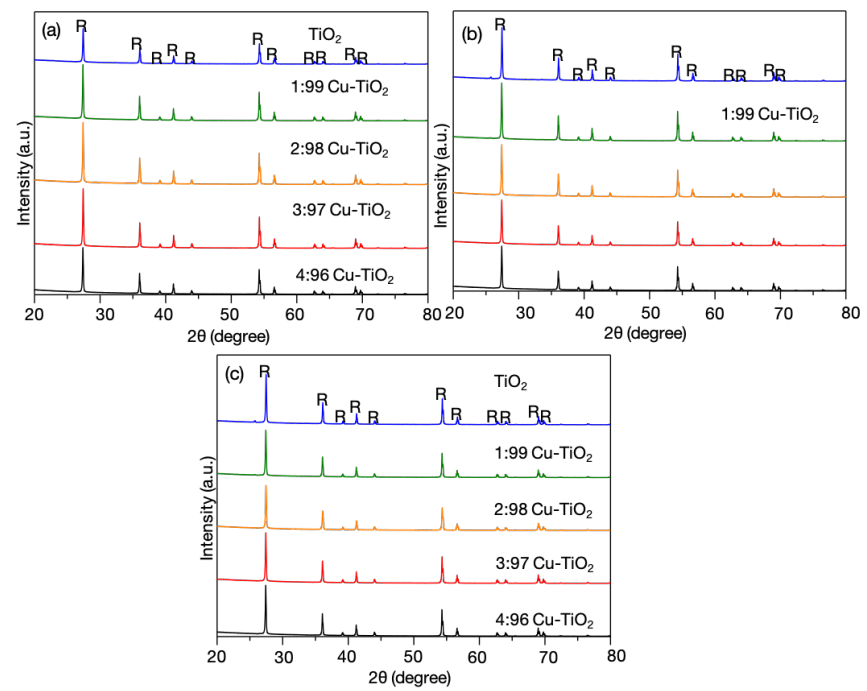

Figure 1. XRD Patterns of $\mathrm{TiO}_{2}$ and Synthesized $\mathrm{Cu} \mathrm{TiO}_{2}$ Samples (1 to $4 \mathrm{~mol} \%$ of $\mathrm{Cu}$ in $\mathrm{TiO}_{2}$ ) Via (a) Sonochemical Method, (b) Impregnation Method and (c) Physical Mixing Method; $\mathrm{R}=$ Rutile Phase

different methods. The XRD patterns were fitting well with the standard data of rutile $\mathrm{TiO}_{2}$ which referenced from the Joint Committee on Powder Diffraction Standard (JCPDS Card No. 21-1276). This could be due to the small amount of $\mathrm{Cu}$ dopant in the prepared samples. With the doping of $\mathrm{Cu}$ to the titania, it was noticed that either strong or weak peaks of the rutile phase still could be identified easily as there were total 11 peaks originated from each $\mathrm{Cu}-\mathrm{TiO}_{2}$ synthesized sample. The diffraction peaks at $27.40^{\circ}, 36.10^{\circ}, 39.20^{\circ}, 41.33^{\circ}$, $44.00^{\circ}, 54.30^{\circ}, 56.70^{\circ}, 62.70^{\circ}, 64.00^{\circ}, 69.00^{\circ}$ and $69.80^{\circ}$, corresponding to (110), (101), (200), (111), (210), (211), (220), (002), (310), (301), and (112) planes respectively, which denoted the tetragonal structure of titania rutile phase (Phromma et al., 2020). Deviation of peak position was not observed because the $\mathrm{Ti}^{4+}$ substitutional sites were replaced and occupied by $\mathrm{Cu}^{2+}$ dopant ions instead of causing distortion of the lattice structure (Raguram and Rajni, 2019). Furthermore, the ionic radius of $\mathrm{Cu}^{2+}(0.73 \AA)$ was similar to $\mathrm{Ti}^{4+}$ ion $(0.74 \AA)$ which allowed the entry of $\mathrm{Cu}^{2+}$ ion to replace $\mathrm{Ti}$ on $\mathrm{TiO}_{2}$ (Isa et al., 2020).

The crystallite size of the synthesized $\mathrm{Cu}-\mathrm{TiO}_{2}$ samples was calculated using Scherrer equation at ( $\left.\begin{array}{lll}1 & 1 & 0\end{array}\right)$ plane and the results are listed in Table 1. Overall, the crystallite size of $\mathrm{Cu}$ doped samples was smaller than that of $\mathrm{TiO}_{2}$. Upon modification with addition of $\mathrm{Cu}$ dopant, the crystallite size of samples decreased to $47.55 \mathrm{~nm}$ for $\mathrm{Cu}-\mathrm{TiO}_{2}$ with molar ratio 2:98 but slightly increased after more $\mathrm{Cu}$ doping. The $\mathrm{Cu}$ doping successfully reduced the crystallite size of $\mathrm{TiO}_{2}$ by inhibiting the $\mathrm{TiO}_{2}$ crystallite growth. Apart from that, the increase in the $\mathrm{Cu}$ doping ratio enabled the increase in peak intensity which enhanced the crystallinity of doped $\mathrm{TiO}_{2}$ TR595. The state-
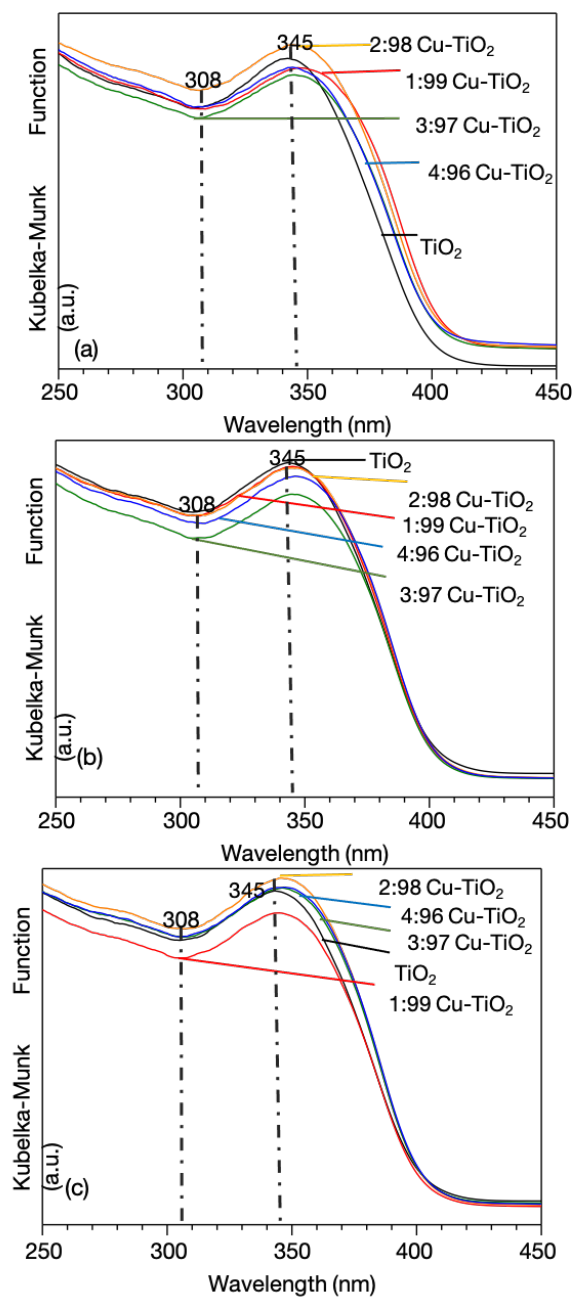

Figure 2. DR-UV-Vis Spectra of $\mathrm{TiO}_{2}$ and The Synthesized $\mathrm{Cu} \mathrm{TiO}_{2}$ Samples Via (a) Sonochemical Method, (b) Impregnation Method and (c) Physical Mixing Method in The Range of $250-450 \mathrm{~nm}$

ment was in accordance with the slight increase in crystallite size obtained when the concentration ratio of $\mathrm{Cu}$ dopant increased and surpassed the optimum level (molar ratio 2:98). Similar results can be referred from another previous report that mentioned that the crystallite size of the samples increased slightly upon addition of $\mathrm{Cu}$ (Rajamannan et al., 2014). In short, the smaller crystallite size of $\mathrm{TiO}_{2}$ TR595 after doping with $\mathrm{Cu}$ in optimum level could increase the surface area as well as the number of active sites which in turn enhanced the transfer rate of surface charge carrier in the photocatalytic activity (Carrera-López and Castillo-Cervantes, 2012; Ooi et al., 2020).

\subsection{Optical Properties}

The optical absorption characteristics of the synthesized samples were performed by DR-UV-Vis analysis. The optical reflectance spectra of $\mathrm{Cu}-\mathrm{TiO}_{2}$ at different molar ratios which 
Table 1. Crystallite Size of $\mathrm{TiO}_{2}$ and The Synthesized $\mathrm{Cu}-\mathrm{TiO}_{2}$ Samples

\begin{tabular}{ccc}
\hline Methods & Synthesized Sample & Crystallite Size/nm \\
\hline \multirow{2}{*}{ Sonochemical } & $\mathrm{TiO}_{2} \mathrm{TR} 595$ & 53.89 \\
& $1: 99 \mathrm{Cu}-\mathrm{TiO}_{2}$ & 50.52 \\
& $2: 98 \mathrm{Cu}-\mathrm{TiO}_{2}$ & 47.55 \\
& $3: 97 \mathrm{Cu}-\mathrm{TiO}_{2}$ & 50.52 \\
& $4: 96 \mathrm{Cu}-\mathrm{TiO}_{2}$ & 53.89 \\
\hline Impregnation & $1: 99 \mathrm{Cu}-\mathrm{TiO}_{2}$ & 50.52 \\
& $2: 98 \mathrm{Cu}-\mathrm{TiO}_{2}$ & 47.55 \\
& $3: 97 \mathrm{Cu}-\mathrm{TiO}_{2}$ & 50.52 \\
& $4: 96 \mathrm{Cu}-\mathrm{TiO}_{2}$ & 50.52 \\
\hline \multirow{2}{*}{ Physical Mixing } & $1: 99 \mathrm{Cu}-\mathrm{TiO}_{2}$ & 53.89 \\
& $2: 98 \mathrm{Cu}-\mathrm{TiO}_{2}$ & 47.55 \\
& $3: 97 \mathrm{Cu}-\mathrm{TiO}_{2}$ & 50.52 \\
& $4: 96 \mathrm{Cu}-\mathrm{TiO}_{2}$ & 50.53 \\
\hline
\end{tabular}

synthesized via different methods are depicted in Figure 2 in the range of $250-450 \mathrm{~nm}$.

Based on Figure 2, there was a similar absorption peak at $345 \mathrm{~nm}$ for all the synthesized $\mathrm{Cu}-\mathrm{TiO}_{2}$ samples. Generally, the DR-UV-Vis spectra of typical $\mathrm{TiO}_{2}$ has strong absorption where its peak ranging from $200-400 \mathrm{~nm}$. A broad peak can be observed from range of $550-800 \mathrm{~nm}$ except for $\mathrm{TiO}_{2}$. The broad absorption peak was due to the presence of $\mathrm{Cu}^{+}$or $\mathrm{Cu}^{2+}$ ions which accompanied by the surface plasmon resonance effect (Gondal et al., 2013). The optical absorption properties were enhanced after $\mathrm{Cu}$ doping which caused red shift to happen as the absorption spectra of $\mathrm{TiO}_{2}$ were shifted towards longer wavelengths (Biru et al., 2021). This could be explained as the shifting of absorption band towards visible light region after the incorporation of $\mathrm{Cu}$ into $\mathrm{TiO}_{2}$ TR595.

The doping of $\mathrm{Cu}$ slightly decreased the band gap energy of $\mathrm{TiO}_{2}(2.98 \mathrm{eV})$ to around $2.94 \mathrm{eV}$ for $\mathrm{Cu}-\mathrm{TiO}_{2}$ with molar ratios $1: 99,2: 98,3: 97$ and $4: 96$. The results obtained were matched with a previous report that claimed the greater reduction in band gap energy of $\mathrm{TiO}_{2}$ with increasing concentration of dopant which caused by the reason of $\mathrm{Cu}-\mathrm{O}$ interaction with covalent characteristic (Mathew et al., 2018). Moreover, it can be deduced that the addition of $\mathrm{Cu}$ dopant caused the reduction of band gap energy from UV light region to visible light region. The visible light absorption can be attributed to the replacement of $\mathrm{Ti}^{4+}$ from $\mathrm{TiO}_{2}$ lattice by $\mathrm{Cu}^{2+} / \mathrm{Cu}^{+}$and caused the formation of mid gap energy levels in the synthesized samples along with formation of oxygen vacancies, hence narrowing the band gap value (Bharti et al., 2016).

\subsection{Photoluminescence Study}

Figure 3 illustrates photoluminescence spectra of the selected samples at the excitation wavelength of $310 \mathrm{~nm}$. The lower intensity of photoluminescence spectrum, the lower density of the recombination centres in a material, leading to low recombination rate of electron-hole pairs. As noticed from Figure 3, $\mathrm{Cu}-\mathrm{TiO}_{2}$ with molar ratio 2:98 synthesized via sonochemical method has the lowest emission intensity while $\mathrm{TiO}_{2}$ TR595 has the highest emission intensity. A reduction of $48.59 \%$ in emission intensity was observed in $\mathrm{Cu}-\mathrm{TiO}_{2}$ synthesized by sonochemical method as compared with $\mathrm{TiO}_{2}$ TR595. This could be due to the improvement of charge separation by ultrasonication through generation of more hydroxyl radicals which thus reducing the electron-hole recombination rate (Sivakumar et al., 2010) .

A broad peak in spectrum was appeared for each $\mathrm{Cu}-\mathrm{TiO}_{2}$ sample which was similar as the peak location discovered in $\mathrm{TiO}_{2}$ TR595. The broad peaks were located at the range around 500 to $650 \mathrm{~nm}$ with the peaks of $\mathrm{Cu}-\mathrm{TiO}_{2}$ were situated at approximately $550 \mathrm{~nm}$. This was due to the occurrence of electrons self-trapping by octahedral shape of $\mathrm{TiO}_{6}$ (Alotaibi et al., 2020). The results obtained were similar to another study using different $\mathrm{Cu}$-doping concentrations with $\mathrm{TiO}_{2}$ to get the photoluminescence emission spectra (Alotaibi et al., 2020).

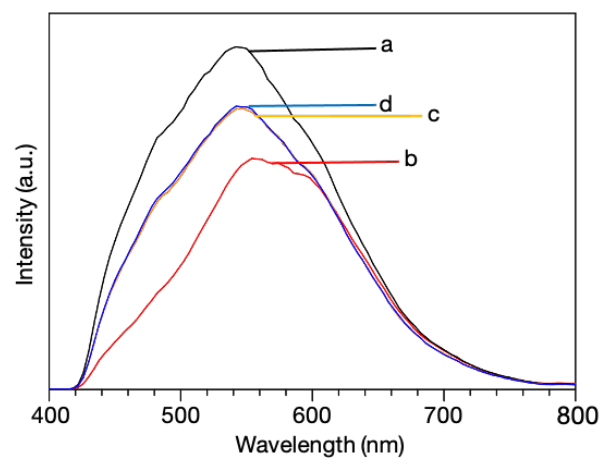

Figure 3. Photoluminescence Spectra of (a) $\mathrm{TiO}_{2} \mathrm{TR} 595$, (b) 2:98 Cu- $\mathrm{TiO}_{2}$ Sonochemical, (c) $2: 98 \mathrm{Cu}-\mathrm{TiO}_{2}$ Impregnation and (d) 2:98 Cu- $\mathrm{TiO}_{2}$ Physical Mixing

Moreover, the addition of $\mathrm{Cu}$ dopant decreased the photoluminescence intensity efficiently as compared with pure $\mathrm{TiO}_{2}$ TR595. It can be explained as effective inhibition of the photogenerated electron to be recombined from conduction band to valance band of $\mathrm{TiO}_{2}$ (Reda et al., 2020). Since $\mathrm{Cu}^{2+}$ ions were well doped into $\mathrm{TiO}_{2}$ structure, some undesired $\mathrm{Cu}-\mathrm{Cu}$ interactions were acted as luminescent quencher to make the emission intensity to decline (Raguram and Rajni, 2019). $\mathrm{Cu}-\mathrm{TiO}_{2}$ with molar ratio 2:98 synthesized via sonochemical method has the slowest electron-hole recombination speed which revealed its top effectiveness in the highest reduction in photoluminescence peak intensity.

\subsection{Morphology Study}

Figure 4 shows the FESEM images of the selected sample of 2:98 $\mathrm{Cu}-\mathrm{TiO}_{2}$ synthesized via sonochemical method. As observed in Figure 4 (a) and (b), it can be deduced that the 
Cu doping did not change the morphology much although the $\mathrm{Cu}^{2+}$ ions were incorporated into the $\mathrm{TiO}_{2}$ matrix (Raguram and Rajni, 2019). The size range of $\mathrm{TiO}_{2} \mathrm{TR} 595$ was between $130 \mathrm{~nm}$ and $250 \mathrm{~nm}$. Meanwhile, the size of $\mathrm{Cu}-\mathrm{TiO}_{2}$ sample observed from the FESEM image was estimated in the range from 120 to $240 \mathrm{~nm}$.
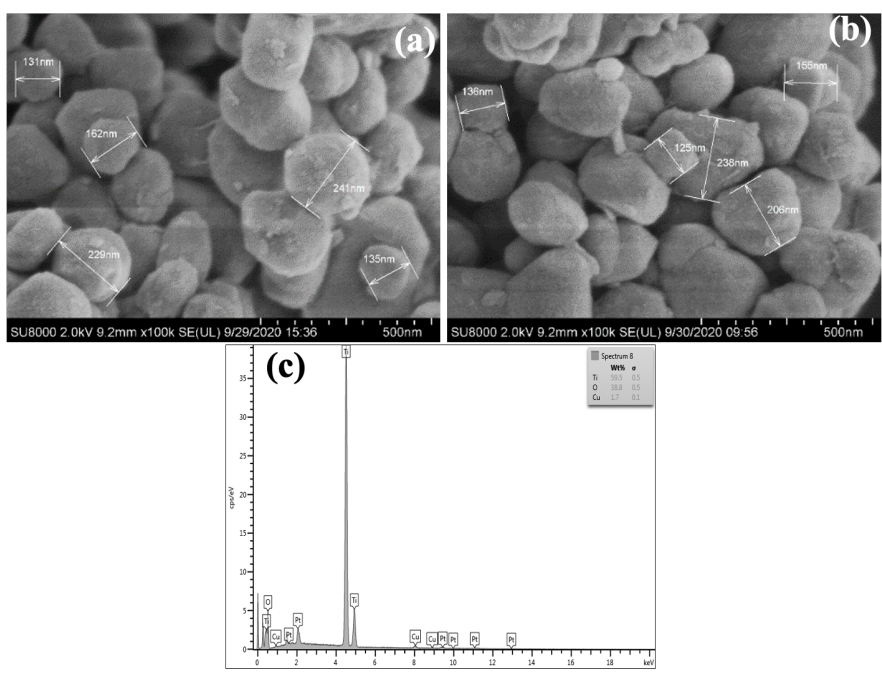

Figure 4. FESEM Images of (a) $\mathrm{TiO}_{2} \mathrm{TR} 595$, (b) 2:98 $\mathrm{Cu}-\mathrm{TiO}_{2}$ Sonochemical and (c) EDX Spectrum of 2:98 $\mathrm{Cu}-\mathrm{TiO}_{2}$ Sonochemical

The size variation was possibly caused by the doping of $\mathrm{Cu}$ into some $\mathrm{TiO}_{2}$ surfaces which made the suppression of $\mathrm{TiO}_{2}$ by grain boundaries resistivity (Biru et al., 2021). As a result, it was clearly seen that some $\mathrm{Cu}-\mathrm{TiO}_{2}$ particles were smaller than those did not covered by $\mathrm{Cu}$ dopant. Based on the EDX spectrum in Figure 4 (c), there was an obvious strong peak for element $\mathrm{Ti}$ of $\mathrm{Cu}-\mathrm{TiO}_{2}$ with molar ratio 98:2 which located at $4.5 \mathrm{keV}$ as well as some weak peaks witnessed at 0.4 and $5.0 \mathrm{keV}$. Furthermore, the element $\mathrm{O}$ was found at peak 0.5 $\mathrm{keV}$ while the element $\mathrm{Cu}$ was noticed peaks approximately at $1.0,8.0$ and $9.0 \mathrm{keV}$ for the respective sample. There was no peak of nitrate found in the spectrum where the nitrate came from the precursor $\mathrm{Cu}\left(\mathrm{NO}_{3}\right)_{2} \cdot 3 \mathrm{H}_{2} \mathrm{O}$. Besides, there were three significant compositions including $59.5 \mathrm{wt} \%$ of $\mathrm{Ti}, 38.8 \mathrm{wt} \%$ of $\mathrm{O}$ and $1.7 \mathrm{wt} \%$ of $\mathrm{Cu}$ that originated from the quantitative results of elements which made up total $100 \mathrm{wt} \%$.

\subsection{Photocatalytic Testing}

Photodegradation of Rhodamine $\mathrm{B}$ under visible light irradiation was conducted to evaluate the photocatalytic performance of the synthesized $\mathrm{Cu}-\mathrm{TiO}_{2}$ samples. The obtained absorbance at $553 \mathrm{~nm}$ was used to calculate the photodegradation efficiency of the synthesized samples.

As depicted in Table $2, \mathrm{Cu}-\mathrm{TiO}_{2}$ with molar ratios of 1:99, 2:98, 3:97 and 4:96 have higher photodegradation performances as compared to unmodified $\mathrm{TiO}_{2}$ TR595. The lowest photocatalytic activity of $\mathrm{TiO}_{2} \mathrm{TR} 595$ was due to its large band gap values $(2.98 \mathrm{eV})$ as shown in the DR UV-Vis analysis. As a result, the visible light uptake by $\mathrm{TiO}_{2} \mathrm{TR} 595$ particles was very limited, leading to its low photocatalytic activity under visible light irradiation (Reda et al., 2020).

Therefore, the addition of $\mathrm{Cu}$ transition metal could enhance the photocatalytic activity of $\mathrm{TiO}_{2}$. It can be explained as $\mathrm{Cu}$ dopant served as a trapping site for photogenerated electrons to increase the electron-hole pairs' lifetime as well as raised the chance of reactions to produce reactive oxygen species (Kerkez and Boz, 2014). In addition, the $\mathrm{Cu}$ dopant also served as an intermediate level of visible light electron excitation for the electron movement from valence band to conduction band after getting sufficient energy from visible light (Biru et al., 2021).

Table 2. Photodegradation Efficiency of $\mathrm{TiO}_{2}$ and The Synthesized Samples

\begin{tabular}{ccc}
\hline \multirow{2}{*}{ Methods } & Samples & $\begin{array}{c}\text { Photodegradation } \\
\text { efficiency (\%) }\end{array}$ \\
\hline \multirow{2}{*}{ Sonochemical } & 1:99 $\mathrm{TiO}-\mathrm{TiO}_{2}$ & 54 \\
& $2: 98 \mathrm{Tu}-\mathrm{TiO}_{2}$ & 61 \\
& $3: 97 \mathrm{Cu}-\mathrm{TiO}_{2}$ & 58 \\
& $4: 96 \mathrm{Cu}-\mathrm{TiO}_{2}$ & 58 \\
\hline \multirow{2}{*}{ Impregnation } & $1: 99 \mathrm{Cu}-\mathrm{TiO}_{2}$ & 61 \\
& $2: 98 \mathrm{Cu}-\mathrm{TiO}_{2}$ & 63 \\
& $3: 97 \mathrm{Cu}-\mathrm{TiO}_{2}$ & 58 \\
& $4: 96 \mathrm{Cu}-\mathrm{TiO}_{2}$ & 57 \\
\hline Physical Mixing & $1: 99 \mathrm{Cu}-\mathrm{TiO}_{2}$ & 60 \\
& $2: 98 \mathrm{Cu}-\mathrm{TiO}_{2}$ & 62 \\
& $3: 97 \mathrm{Cu}-\mathrm{TiO}_{2}$ & 58 \\
& $4: 96 \mathrm{Cu}-\mathrm{TiO}_{2}$ & 58 \\
\hline
\end{tabular}

Noticeably, there was subsequent increase in the photocatalytic activity when the amount of $\mathrm{Cu}$ dopant increased from 1 to 2 molar ratio in the samples. Interestingly, all $\mathrm{Cu}-\mathrm{TiO}_{2}$ samples with molar ratio of 2:98 showed the best photocatalytic activity of $65 \%, 63 \%$ and $62 \%$ in their series which synthesized via sonochemical, impregnation and physical mixing methods, respectively. This could be attributed to the smaller crystallite size and particle size of these samples as evidenced by the XRD and FESEM analyses. It is widely accepted that smaller particle size is crucial for a larger surface area of the sample in order to increase the number of active sites, thus leading to the highest photocatalytic efficiency. The current findings suggested that more reactive oxygen species such as $\mathrm{OH}$ radicals would be produced through the sonochemical synthesis method. It is expected that the ultrasonication process has increased efficiency of charge separation and decreased the speed of electron-hole 
recombination (Sivakumar et al., 2010).

When the molar ratio of $\mathrm{Cu}$ increased above the optimum level ( $2 \mathrm{~mol} \%$ ), the continuous addition of $\mathrm{Cu}$ did not beneficial to the photocatalytic activity of $\mathrm{TiO}_{2}$. The excess amount of $\mathrm{Cu}^{2+}$ ions were unable to diffuse into lattice structure of $\mathrm{TiO}_{2}$, but only deposited on the surface area (Biru et al., 2021). This led to the blockage of active sites of $\mathrm{TiO}_{2}$ which hindered the penetration of light reaching on $\mathrm{TiO}_{2}$ surface (Riaz et al., 2014). The inhibition of photocatalytic activity happened since the number of photogenerated electrons and holes also declined. Apart from that, another report stated that when the metal loading kept on increasing, it caused the occurrence of metal particles to agglomerate and hence reduced the photocatalytic performance of the photocatalyst (Koh et al., 2017). Thus, the reasons above explained the decrease in photodegradation percentages for $\mathrm{Cu}-\mathrm{TiO}_{2}$ of molar ratios 3:97 and 4:96. In short, the modification of $\mathrm{Cu}$ dopant on $\mathrm{TiO}_{2}$ was able to enhance to photocatalytic activity but if only doped with the optimum amount without excess.

\section{CONCLUSIONS}

$\mathrm{CuO}$ doped $\mathrm{TiO}_{2}$ photocatalysts of different molar ratios were successfully synthesized via three different methods including sonochemical, impregnation and physical mixing methods. The XRD analysis proved the presence of rutile $\mathrm{TiO}_{2}$ in the samples and smaller crystallite size of $\mathrm{Cu}-\mathrm{TiO}_{2}$ were obtained due to broadening effect after the incorporation of $\mathrm{Cu}$ into $\mathrm{TiO}_{2}$ matrix. Reduction of band gap energy with $\mathrm{Cu}$ dopants were observed under Tauc plots, lower recombination of electron hole pairs was discovered under photoluminescence analysis and reduction of particle size of $\mathrm{Cu}-\mathrm{TiO}_{2}$ were justified via FESEM analysis. The formation of new energy level in $\mathrm{Cu}-\mathrm{TiO}_{2}$ allowed these $\mathrm{CuO}$ doped $\mathrm{TiO}_{2}$ samples to be active in visible region. Among all the samples, $\mathrm{Cu}-\mathrm{TiO}_{2}$ of molar ratio of 2:98 synthesized via sonochemical method achieved the best photocatalytic performance of $65 \%$ photodegradation of Rhodamine B under visible light irradiation. It has been demonstrated that the high photodegradation efficiency was due to the high crystallinity, smaller particle size with larger surface area of the sample, lower band gap energy as well as lower recombination rate of electron-hole pairs.

\section{ACKNOWLEDGEMENT}

The authors are grateful to the Ministry of Higher Education (MOHE), Malaysia and Universiti Teknologi Malaysia for the financial support given under UTM High Impact Research Grant (Cost Center No. QJ130000.2454.08G53).

\section{REFERENCES}

Alotaibi, A. M., B. A. Williamson, S. Sathasivam, A. Kafizas, M. Alqahtani, C. Sotelo-Vazquez, J. Buckeridge, J. Wu, S. P. Nair, D. O. Scanlon (2020). Enhanced Photocatalytic and Antibacterial Ability of Cu-Doped Anatase $\mathrm{TiO}_{2}$ Thin Films:
Theory and Experiment. ACS Applied Materials and Interfaces, 12(13); 15348-15361

Bharti, B., S. Kumar, H.-N. Lee, and R. Kumar (2016). Formation of Oxygen Vacancies and $\mathrm{Ti}^{3+}$ State in $\mathrm{TiO}_{2}$ Thin Film and Enhanced Optical Properties by Air Plasma Treatment. Scientific Reports, 6(1); 1-12

Biru, M., J. Qaderi, C. R. Mamat, and A. A. Jalil (2021). Preparation and Characterization of Copper, Iron, and Nickel Doped Titanium Dioxide Photocatalysts for Decolorization of Methylene Blue. Sains Malaysiana, 50(1); 135-149

Carrera-López, R. and S. Castillo-Cervantes (2012). Effect of The Phase Composition and Crystallite Size of Sol-Gel $\mathrm{TiO}_{2}$ Nanoparticles on The Acetaldehyde Photodecomposition. Superficies y Vacio, 25(2); 82-87

Deraz, N. (2018). The Comparative Jurisprudence of Catalysts Preparation Methods: I. Precipitation and Impregnation Methods. Journal of Industrial and Environmental Chemistry, 2(1); 19-21

Gondal, M., M. Dastageer, S. Rashid, S. Zubair, M. Ali, D. Anjum, J. Lienhard, G. McKinley, and K. Varanasi (2013). Plasmon Resonance Enhanced Photocatalysis Under Visible Light with $\mathrm{Au} / \mathrm{Cu}-\mathrm{TiO}$. Science of Advanced Materials, $5 ; 1-8$

Isa, L. et al. (2020). Synthesis and Characterization of Structural Nanocomposite Titanium Dioxide Copper-Doped using The Impregnation Method. Spektra: Jurnal Fisika dan Aplikasinya, 5(1); 21-30

Kerkez, Ö. and İ. Boz (2014). Photo (Electro) Catalytic Activity of $\mathrm{Cu}^{2+}$-Modified $\mathrm{TiO}_{2}$ Nanorod Array Thin Films Under Visible Light Irradiation. Journal of Physics and Chemistry of Solids, 75(5); 611-618

Koh, P. W., M. H. M. Hatta, S. T. Ong, L. Yuliati, and S. L. Lee (2017). Photocatalytic Degradation of Photosensitizing and Non-Photosensitizing Dyes Over Chromium Doped Titania Photocatalysts Under Visible Light. Journal of Photochemistry and Photobiology A: Chemistry, 332; 215-223

Koh, P. W., C. Y. Leong, L. Yuliati, H. Nur, and S. L. Lee (2020). Role of Vanadia and Titania Phases in the Removal of Methylene Blue by Adsorption and Photocatalytic Degradation. Malaysian Journal of Analytical Sciences, 24(6); $1045-$ 1060

Leong, C. Y., Y. S. Lo, P. W. Koh, and S. L. Lee (2021). Synthesis of Titanium Dioxide Nanotubes with Different $\mathrm{N}$-Containing Ligands via Hydrothermal Method. Science and Technology Indonesia, 6(2); 67-73

Mathew, S., P. Ganguly, S. Rhatigan, V. Kumaravel, C. Byrne, S. J. Hinder, J. Bartlett, M. Nolan, and S. C. Pillai (2018). Cu-doped $\mathrm{TiO}_{2}$ : Visible Light Assisted Photocatalytic Antimicrobial Activity. Applied Sciences, 8(11); 2067

Megha, R., Y. Ravikiran, B. Chethan, H. R. Prakash, S. V. Kumari, and S. Thomas (2018). Effect of Mechanical Mixing Method of Preparation of Polyaniline-Transition Metal Oxide Composites on DC Conductivity and Humidity Sensing Response. Journal of Materials Science: Materials in Electronics, 29(9); 7253-7261 
Neena, D., K. K. Kondamareddy, H. Bin, D. Lu, P. Kumar, R. Dwivedi, V. O. Pelenovich, X.-Z. Zhao, W. Gao, and D. Fu (2018). Enhanced Visible Light Photodegradation Activity of RhB/MB from Aqueous Solution Using Nanosized Novel Fe-Cd Co-Modified ZnO. Scientific Reports, 8(1); $1-12$

Ooi, Y. K., M. H. M. Hatta, and S. L. Lee (2020). Properties and Photocatalytic Behaviour of Vanadia Loaded Titania Supported on MCM-41 Synthesized using Different Surfactants for Degradation of Methylene Blue. Journal of the Indonesian Chemical Society, 3(1); 28-28

Ooi, Y. K., L. Yuliati, and S. L. Lee (2016). Phenol Photocatalytic Degradation over Mesoporous TUD-1-supported Chromium Oxide-doped Titania Photocatalyst. Chinese Journal of Catalysis, 37(11); 1871-1881

Phromma, S., T. Wutikhun, P. Kasamechonchung, T. Eksangsri, and C. Sapcharoenkun (2020). Effect of Calcination Temperature on Photocatalytic Activity of Synthesized $\mathrm{TiO}_{2}$ Nanoparticles Via Wet Ball Milling Sol-Gel Method. Applied Sciences, 10(3); 993

Raguram, T. and K. Rajni (2019). Synthesis and analysing the structural, optical, morphological, photocatalytic and magnetic properties of $\mathrm{TiO}_{2}$ and doped (Ni and $\left.\mathrm{Cu}\right) \mathrm{TiO}_{2}$ nanoparticles by sol-gel technique. Applied Physics A: Materials Science \&O Processing, 125(5)

Rajamannan, B., S. Mugundan, G. Viruthagiri, P. Praveen, and N. Shanmugam (2014). Linear and Nonlinear Optical Studies of Bare and Copper Doped $\mathrm{TiO}_{2}$ Nanoparticles Via
Sol Gel Technique. Spectrochimica Acta Part A: Molecular and Biomolecular Spectroscopy, 118; 651-656

Reda, S., M. Khairy, and M. Mousa (2020). Photocatalytic Activity of Nitrogen and Copper Doped $\mathrm{TiO}_{2}$ Nanoparticles Prepared by Microwave-Assisted Sol-Gel Process. Arabian Journal of Chemistry, 13(1); 86-95

Riaz, N., C. F. Kait, Z. Man, B. K. Dutta, R. M. Ramli, and M. S. Khan (2014). Visible Light Photodegradation of Azo Dye by $\mathrm{Cu} / \mathrm{TiO}_{2}$. Advanced Materials Research, 917; 151159

Sabran, N. H., L. Yuliati, S. L. Lee, and H. O. Lintang (2019). Systematic Study of Calcination Temperature on Photocatalytic Activity of Luminescent Copper(I) Pyrazolate Complex/Titanium Oxide Composites. Journal of the Indonesian Chemical Society, 2(1); 54

Sahrin, N. T., R. Nawaz, C. Fai Kait, S. L. Lee, and M. D. H. Wirzal (2020). Visible Light Photodegradation of Formaldehyde Over $\mathrm{TiO}_{2}$ Nanotubes Synthesized Via Electrochemical Anodization of Titanium Foil. Nanomaterials, 10(1); 128

Sivakumar, M., A. Towata, K. Yasui, T. Tuziuti, T. Kozuka, and Y. Iida (2010). Dependence of Sonochemical Parameters on The Platinization of Rutile Titania - An Observation of a Pronounced Increase in Photocatalytic Efficiencies. $\mathrm{Ul}$ trasonics Sonochemistry, 17(3); 621-627

Zuas, O. and H. Budiman (2013). Synthesis of Nanostructured Copper-Doped Titania and its Properties. Nano-Micro Letters, 5(1); 26-33 